\title{
Testing the Medina embolization device in experimental aneurysms
}

\author{
Robert Fahed, MD, MSc, ${ }^{1}$ Tim E. Darsaut, MD, MSc, ${ }^{2}$ Igor Salazkin, MD, ${ }^{1}$ Guylaine Gevry, BSc, ${ }^{1}$ and \\ Jean Raymond, MD ${ }^{1,3}$ \\ ${ }^{1}$ Interventional Neuroradiology Laboratory, Research Centre, Centre Hospitalier de l'Université de Montréal (CHUM), Montreal, \\ Quebec; ${ }^{2}$ Division of Neurosurgery, Department of Surgery, Mackenzie Health Sciences Centre, University of Alberta Hospital, \\ Edmonton, Alberta; and ${ }^{3}$ Service of Neuroradiology, Department of Radiology, Centre Hospitalier de l'Université de Montréal \\ (CHUM), Montreal, Quebec, Canada
}

OBJECTIVE The Medina embolization device (MED) is a novel, braided self-expanding endovascular device designed to occlude aneurysms by constructing an in situ intrasaccular flow diverter. Although a single device can be positioned at the neck of simple spherical in vitro aneurysms, the best way to occlude more complex in vivo aneurysms (using multiple MEDs or a combination of MEDs and platinum coils) is currently unknown.

METHODS Fifty-two aneurysms of 3 different types were created in 31 canines, yielding 48 patent aneurysms. Treatments were randomly allocated by drawing lots: group 1, MEDs alone $(n=16)$; group 2, MEDs plus standard platinum coils $(n=16)$; and group 3, control aneurysms treated with coils alone $(n=16)$. Angiographic results were scored and compared immediately following treatment completion and at 3 months. Specimens were photographed and the extent of neointimal closure of the aneurysmal neck scored, followed by histopathological analyses.

RESULTS Angiographic scores of 0 or 1 (occlusion or near occlusion) were initially obtained in 2 of $16(12.5 \%, 95 \%$ Cl 1.6\%-38.3\%) group 1 (MEDs alone), 3 of 16 (18.7\%, 95\% Cl 4\%-45.6\%) group 2 (MEDs plus coils), and 10 of 16 $(62.5 \%, 95 \% \mathrm{Cl} 35.4 \%-84.8 \%)$ group 3 (coils alone) aneurysms ( $p=0.005)$. At 3 months, scores of 0 or 1 were found in 11 of $16(68.7 \%, 95 \% \mathrm{Cl} 41.3 \%-89.0 \%)$ group 1, 9 of $16(56.2 \%, 95 \% \mathrm{Cl} 29.9 \%-80.2 \%)$ group 2, and 8 of $16(50 \%, 95 \%$ $\mathrm{Cl} 24.7 \%-75.3 \%)$ group 3 aneurysms ( $p=0.82$ ). Neointimal scores were similar for the 3 treated groups $(p=0.66)$.

CONCLUSION Endovascular treatment of experimental aneurysms with MEDs or MEDs and coils showed angiographic occlusion and neointimal scores at 3 months that were similar to those achieved with standard platinum coiling.

https://thejns.org/doi/abs/10.3171/2018.5.JNS18326

KEYWORDS experimental aneurysm; intrasaccular flow disruptor; endovascular device; endovascular coil; animal models; vascular disorders

$\mathrm{E}$ NDOVASCULAR embolization is increasingly used to treat intracranial aneurysms. ${ }^{4}$ One drawback of this minimally invasive technique is the rate of recurrences after treatment. ${ }^{19}$ Second-generation surface-modified coils have been designed to overcome this problem, but none have convincingly been shown to decrease recurrences. ${ }^{15,20,24}$ Another strategy is to treat the neck of the aneurysm by treating the parent artery with a stent or a flow diverter (FD), where a braided mesh device is placed across the neck, with or without placing coils in the aneurysm. However, the use of intra-arterial stents and FDs re- quires dual antiplatelet therapy to prevent thromboembolic complications, and the associated hemorrhagic risks can limit their use, particularly in the context of subarachnoid hemorrhage..$^{13}$ In addition, stents and FDs have yet to show clinical benefits as compared to coiling in a randomized trial. 5,18

Self-expanding braided intrasaccular devices, sometimes called intrasaccular flow disruptors (IFDs), have more recently been developed; they do not require dual antiplatelet therapy, and are intended to close the neck of the aneurysm with a low-porosity metallic mesh from the

ABBREVIATIONS ASA = acetylsalicylic acid; CCA = common carotid artery; FD = flow diverter; HPS = hematoxylin, phloxine, and saffron; IFD = intrasaccular flow disruptor; MED = Medina embolization device.

SUBMITTED February 5, 2018. ACCEPTED May 10, 2018.

INCLUDE WHEN CITING Published online November 2, 2018; DOI: 10.3171/2018.5.JNS18326. 
inside of the aneurysm sac. ${ }^{1,3}$ In contrast to platinum coiling, where the introduction of coils of various diameters and lengths gradually fills the aneurysmal sac to conform to the aneurysm morphology, the IFD must be precisely selected in advance to fit the individual aneurysm size and shape, an exacting task. ${ }^{3}$ Because devices of a given shape come in a limited variety of sizes, it is almost as if patients and aneurysms have to be selected to fit the size of available devices. ${ }^{3}$ Delivery currently requires relatively large microcatheters, and sudden device expansion from its compacted state in the catheter lumen to a large intrasaccular metallic cage as a single unit upon deployment is of concern when aneurysms are small or recently ruptured. ${ }^{16}$

Similar to IFDs, Medina embolization devices (MEDs) are also intended to divert flow and close the aneurysm neck with a metallic structure placed inside the aneurysm cavity, but not with a one-time expansion of a device of a given shape; as with coils, the MED structure is progressively built in situ, aiming for a less traumatic deployment that may be more adaptable to the morphology of the individual aneurysm. The MED is composed of several "petals" of self-expanding low-porosity mesh made from braided nitinol wires linked one to another. Petals of the device are deployed one by one in a rolling fashion such that the petals form a spheroid structure that closes the aneurysm neck with a layer of low-porosity mesh. The best way to construct this intrasaccular neck-closing structure, with a single or multiple MEDs, or using a combination of MEDs and platinum coils, remains unknown. Several case series detailing the clinical use of MEDs have already shown problems in achieving satisfactory angiographic results, ${ }^{1,2,22,23}$ but no preclinical studies have been reported.

The goals of this work were 1) to compare angiographic and pathological results of this new approach with results obtained by means of more standard treatment with platinum coils and 2) to determine the best way to effectively use the MED to close the neck of experimental aneurysms of various configurations, sizes, and shapes by comparing the use of MEDs alone to a combination of MEDs and coils.

\section{Methods}

The present report was prepared in accordance with the ARRIVE guidelines for animal research. ${ }^{12}$ Protocols for animal experimentation were approved by the institutional Animal Care Committee in accordance with guidelines of the Canadian Council on Animal Care. All procedures were performed in 22- to 32-kg canines under general anesthesia.

\section{Surgical Aneurysm Creation}

To create a variety of aneurysm sizes and configurations that mimic the heterogeneity of clinically encountered cases, 3 different types of experimental aneurysms were created in 31 animals. Briefly, through a paramedian cervical incision, the left external jugular vein was harvested, inverted to remove valves, and placed in heparinized saline. Under temporary clip flow arrest, the vein graft(s) were then anastomosed to the carotid artery, using continuous 7.0 Prolene sutures (Ethicon), to form 6 lateral wall common carotid artery (CCA) aneurysms (bilateral aneurysms in 3 animals), ${ }^{10} 10$ T-bifurcation CCA aneurysms (10 aneurysms in 10 animals), ${ }^{21}$ and 36 lingual artery bifurcation aneurysms (bilateral aneurysms in 18 animals). ${ }^{8}$ Details of these surgical procedures have previously been published. ${ }^{8,10,21}$ Incisions were closed in multiple layers over a drain left in place for 24 hours. Further details regarding animal anesthesia, housing, husbandry conditions, and welfare are available on request.

\section{Endovascular Treatment}

Catheter angiography was performed 4-6 weeks after aneurysm construction, using a percutaneous transfemoral approach. Aneurysm and arterial dimensions were measured on a Siemens Leonardo workstation, using Syngo software. Patent aneurysms were randomly allocated to one of 3 treatment groups by drawing lots: group 1 aneurysms were to be treated with MEDs only $(\mathrm{n}=16)$; group 2 were to be treated with a combination of a "framer" MED filled with platinum coils $(n=16)$; group 3 were control aneurysms to be treated with standard platinum coils only $(\mathrm{n}=16)$ (Fig. 1). The number of aneurysms was selected to detect a significant decrease (with a power of $80 \%$ and alpha error of $5 \%$ ) in the proportion of residual aneurysms at 3 months, from $50 \%$ with coiling to $10 \%$ with MED, taking into account the randomization ratio (2:1), $10 \%$ potential losses, and considerations of cost and animal use ethics.

The initial "framer" MED used in groups 1 and 2 was of a size selected to best approximate the width of the aneurysm; it was deployed and then repositioned as needed in an attempt to close the neck and achieve contrast stagnation within the aneurysm sac. The decision to detach the first "framing" device was made only when the best possible position had been attained, in terms of covering the aneurysm neck as fully as possible. In group 1, shorter "filling" MEDs of a smaller size were then used to attempt to complete the construction of the intrasaccular flow disruptor, while in group 2, platinum coils were used to attempt to achieve the same result. For each aneurysm, the embolization was stopped when satisfactory intraaneurysmal contrast disruption/stagnation was obtained, or when it was felt that no additional coil/MED could be deployed inside the aneurysm. Some group 2 aneurysms with very wide necks necessitated 2 "framing MEDs" to facilitate platinum coiling without protrusion into the parent artery. Group 3 aneurysms were filled as completely as possible with platinum coils, using standard techniques.

In 3 cases (1 lingual bifurcation aneurysm and $2 \mathrm{~T}$ bifurcation aneurysms) 2 to 5 coils were initially used to pack the fundus of long aneurysm sacs to remodel the aneurysm to a more spherical shape. This initial procedure did not change treatment assignment. The use of adjunct balloons (Hyperglide $4 \mathrm{~mm} \times 15 \mathrm{~mm}$ [Medtronic]) or bail-out stents (LVIS $4.5 \mathrm{~mm} \times 23 \mathrm{~mm}$ [MicroVention]) was permissible when judged necessary. Animals that required bail-out stents $(\mathrm{n}=3)$ were immediately administered acetylsalicylic acid (ASA) $325 \mathrm{mg}$ and clopidogrel $75 \mathrm{mg}$ for 10 days post-implantation, followed by ASA alone until euthanasia.

Angiographic series were acquired immediately after 
Fahed et al.

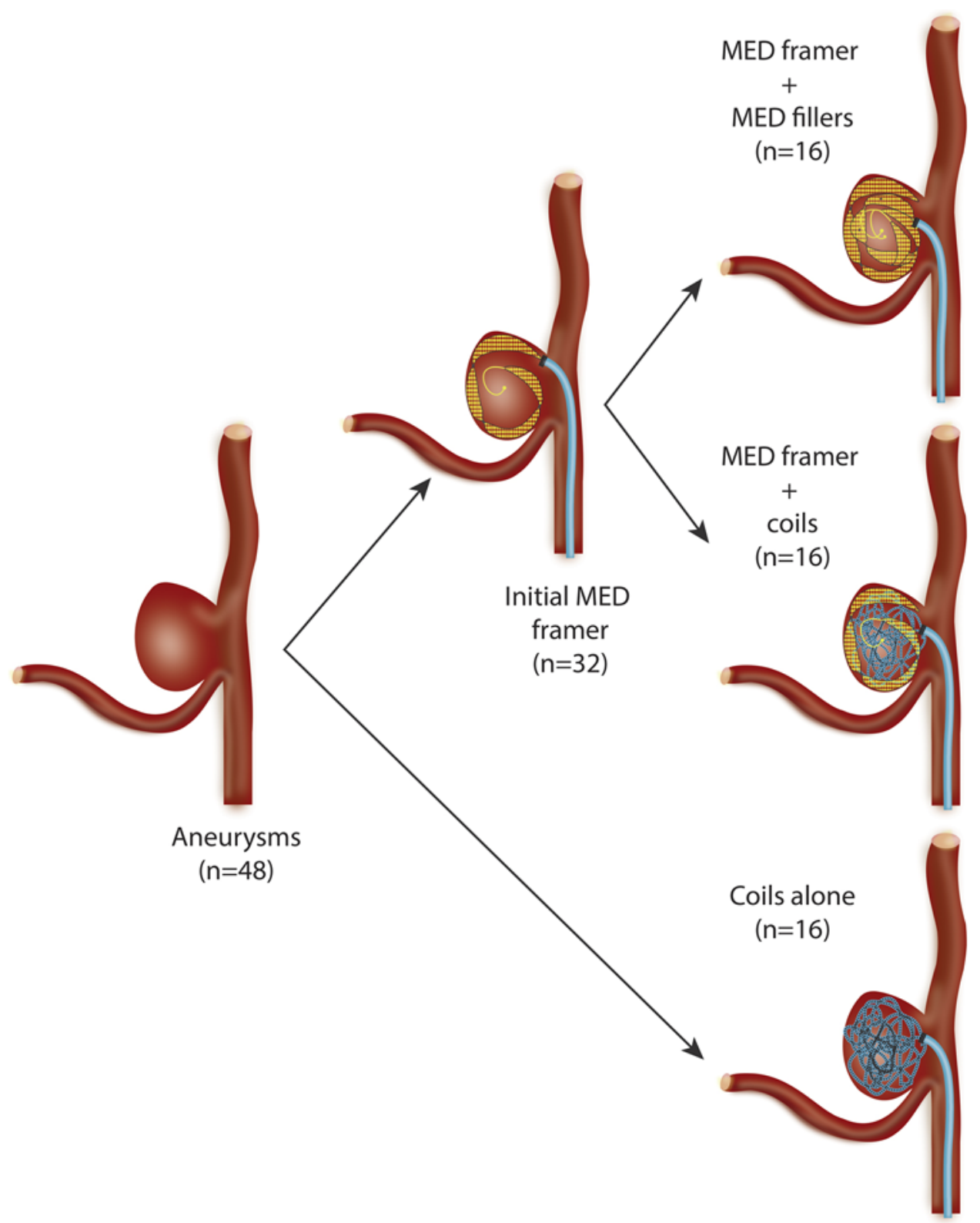

FIG. 1. Schematized flowchart to show disposition of experimental aneurysms, with randomized allocation to various treatment groups. Copyright Jean Raymond. Published with permission. Figure is available in color online only.

endovascular treatment, as well as 3 months later, followed by euthanasia. The degree of aneurysm occlusion was scored by 2 independent raters (J.R. and T.E.D.) according to an ordinal scale, with 0 indicating complete aneurysm occlusion; 1 , residual neck; 2 , residual aneurysm $\leq 50 \%$; 3 , residual aneurysm $>50 \%$; and 4 , widely patent aneurysm: ${ }^{11}$ Discrepancies were resolved in a consensus session. Results were dichotomized (scores 0 and 1 vs $2-4)$.

\section{Pathology}

The carotid aneurysm constructs were harvested en bloc, fixed in 10\% formalin for 5-7 days, and then sectioned and photographed using a computerized imaging system (Motic Images Advanced 3.2). The arterial wall immediately facing the aneurysm neck was longitudinally opened, and photographed en face. Neointimal closure of the aneurysm neck was graded according to a previously described classification system. ${ }^{21} \mathrm{~A}$ score of 0 was assigned when thick neointima completely sealed the orifice of the aneurysmal neck; 1 , when neointima almost completely sealed the neck, with small openings only; 2 , when neointima partially sealed the neck but with major defects in some areas; 3 , for partial neointimal neck coverage only; 4 , when there was no neointima (thrombus only). Results were dichotomized ( 0 and 1 vs $2-4$ ) for comparisons between groups. Biopsies of neointima covering the devices, and sections of aneurysm or arterial wall were embedded 
TABLE 1. Aneurysm characteristics per randomly allocated treatment group

\begin{tabular}{|c|c|c|c|c|}
\hline Group \& Characteristic & $\begin{array}{l}\text { Lat Wall Carotid } \\
\text { Aneurysms }\end{array}$ & $\begin{array}{l}\text { Carotid T-Bifurcation } \\
\text { Aneurysms }\end{array}$ & $\begin{array}{l}\text { Lingual Bifurcation } \\
\text { Aneurysms }\end{array}$ & $\begin{array}{c}\text { Total No., Mean } \\
\text { Dimensions }\end{array}$ \\
\hline \multicolumn{5}{|l|}{ Group 1 (MEDs only) } \\
\hline Aneurysms (n) & 2 & 3 & 11 & 16 \\
\hline Mean aneurysm height (mm) & $14.3 \pm 11.4$ & $13.2 \pm 1.1$ & $9.8 \pm 2.7$ & $11.0 \pm 4.1$ \\
\hline Mean aneurysm width (mm) & $13.6 \pm 3.7$ & $6.8 \pm 1.8$ & $6.9 \pm 1.7$ & $7.7 \pm 2.9$ \\
\hline Mean neck size (mm) & $10.3 \pm 0.6$ & $5.4 \pm 2.6$ & $5.8 \pm 1.9$ & $6.3 \pm 2.4$ \\
\hline \multicolumn{5}{|l|}{ Group 2 (MEDs + coils) } \\
\hline Aneurysms (n) & 1 & 4 & 11 & 16 \\
\hline Mean aneurysm height (mm) & 9.4 & $13.1 \pm 3.3$ & $9.2 \pm 4.6$ & $10.1 \pm 4.4$ \\
\hline Mean aneurysm width (mm) & 16.9 & $7.0 \pm 1.1$ & $7.5 \pm 2.3$ & $8.0 \pm 3.0$ \\
\hline Mean neck size (mm) & 12.5 & $5.0 \pm 1.0$ & $6.6 \pm 2.4$ & $6.5 \pm 2.7$ \\
\hline \multicolumn{5}{|l|}{ Group 3 (coils alone) } \\
\hline Aneurysms (n) & 3 & 3 & 10 & 16 \\
\hline Mean aneurysm height $(\mathrm{mm})$ & $12.2 \pm 7.4$ & $15.7 \pm 0.3$ & $11.4 \pm 2.9$ & $12.3 \pm 3.9$ \\
\hline Mean aneurysm width (mm) & $11.9 \pm 1.7$ & $6.5 \pm 0.4$ & $7.1 \pm 2.3$ & $7.9 \pm 2.8$ \\
\hline Mean neck size (mm) & $12.2 \pm 1.3$ & $6.0 \pm 1.1$ & $5.0 \pm 0.6$ & $6.5 \pm 2.9$ \\
\hline
\end{tabular}

in paraffin, and stained with hematoxylin, phloxine, and saffron (HPS) or Movat's pentachrome for microscopic study, as previously. ${ }^{21}$

\section{Statistics}

Aneurysms dimensions, angiographic occlusion, and histopathology scores were compared using ANOVAs or Kruskal-Wallis tests when appropriate. The significance level was set at $\mathrm{p}=0.05$.

\section{Results}

After 4-6 weeks, initial patency of the surgically constructed aneurysms was as follows: lateral wall CCA, 6 of 6; CCA T-bifurcation, 10 of 10; and lingual bifurcation aneurysms, 32 of 36 (89\%); yielding 48 aneurysms for further experimentation. The mean aneurysm and neck dimensions for each treatment group are presented in Table 1 , with details for individual aneurysms available in Supplementary Table 1 . The 3 different aneurysm models were well distributed with no significant difference between the 3 treatment groups.

Deployment of the first "framing" MED (groups 1 and 2) into the intended spheroid configuration in the necessary position to effectively close the neck with the low-porosity mesh was infrequently successful. A petal that had originally been well placed across the aneurysm neck was often seen to change position when additional petals of the same device were extruded. MEDs could be repeatedly deployed and retrieved without difficulty, and there were no instances of devices fracturing or stretching. However, multiple deployments followed by retrievals sometimes led to failure of the individual petals to re-expand upon extrusion from the microcatheter (Fig. 2). The deployment of the initial or "framing" MED was able to achieve contrast stagnation within the aneurysm in 3 of $16(18.7 \%)$ group 1 aneurysms and 4 of $16(25 \%)$ group 2 aneurysms.
Placement of additional MEDs (group 1) or coils (group 2) strictly within the confines of the framing MED could not readily be accomplished, particularly in wide-necked aneurysms, where additional MEDs were occasionally seen to displace the first framing device, sometimes leading to a petal protrusion in front of an adjacent branch. Similar MED displacements occurred in group 2 when coils were used to attempt to fill the first framing device, and on 1 occasion, MED protrusion into the parent artery required bail-out stenting.

Group 1 aneurysms $(n=16)$ were treated with a mean $( \pm \mathrm{SD})$ of $3.5 \pm 1.8$ MEDs (range $1-8$ per aneurysm, sizes ranging from $5 \times 5 \mathrm{~mm}$ to $9 \times 13 \mathrm{~mm}$ ); group 2 aneurysms $(n=16)$ with a mean of $1.6 \pm 0.9$ MEDs (range $1-4$ per aneurysm, sizes ranging from $6 \times 6 \mathrm{~mm}$ to $9 \times 13 \mathrm{~mm}$ ), plus a mean of $4.4 \pm 1.8$ coils (range $2-9$ coils per aneurysm, dimensions ranging from $2 \times 6 \mathrm{~cm}$ to $14 \times 30 \mathrm{~cm}$ ). Group 3 aneurysms $(n=16)$ were treated with a mean of $7.6 \pm 2.8$ coils (range 3-13 coils per aneurysm, dimensions ranging from $2 \times 6 \mathrm{~cm}$ to $14 \times 40 \mathrm{~cm}$ ).

Balloons were necessary in 6 cases $(1$ in group 1 [MEDs only], 4 in group 2 [MEDs + coils], and 1 in group 3 [coils only]), to contain the coils or MEDs inside the aneurysm without significant protrusion into the parent artery. Bail-out stents were necessary in 3 cases ( 1 in group 1 [MEDs only] and 2 in group 3 [coils only]) to reposition a protruding metallic mass.

Angiographic results immediately following treatment as well as at 3 months after treatment are presented in Table 2 and in Figs. 2-4.

Angiographic scores of 0 and 1 were initially obtained in 2 of $16(12.5 \%, 95 \%$ CI $1.6 \%-38.3 \%)$ group 1 (MEDs), 3 of $16(18.7 \%, 95 \%$ CI $4 \%-45.6 \%)$ group 2 (MEDs plus coils), and 10 of $16(62.5 \%, 95 \%$ CI $35.4 \%-84.8 \%)$ group 3 (coils alone) aneurysms ( $\mathrm{p}=0.005$, Kruskal-Wallis). There were no significant differences in angiographic occlusion scores at 3 months $(p=0.82)$. Scores of $0-1$ were found 


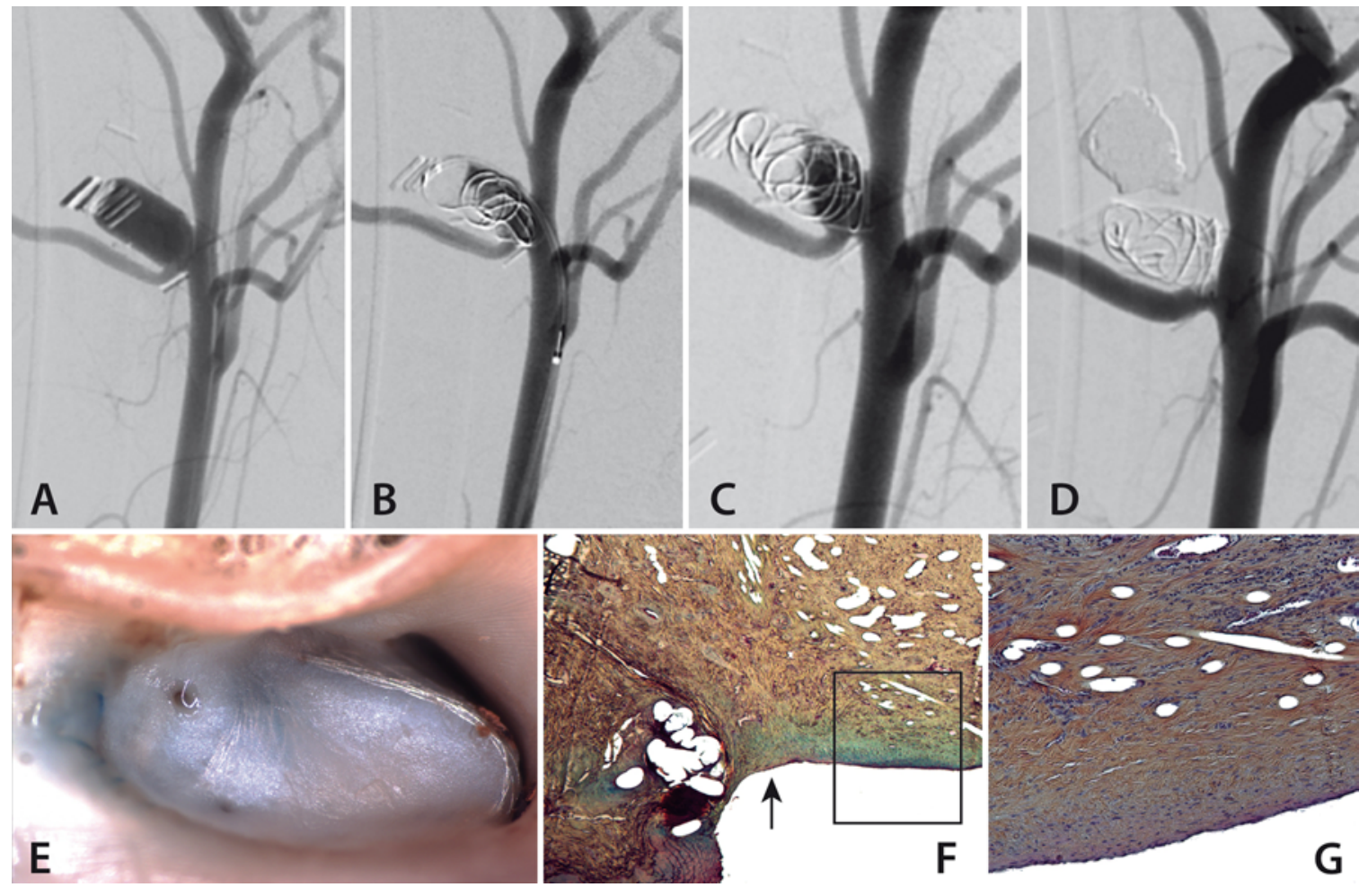

FIG. 2. Experimental aneurysm (A) treated with 2 MEDs (1 framer and 1 filler, B) that showed residual aneurysm opacification immediately after treatment (C) and complete occlusion at 3 months (D). Despite the extrusion of the MED at the neck resulting in branch coverage (B and C), the branch was patent at 3 months' follow-up (D). Pathological analysis showed complete neointimal coverage $(\mathbf{E})$, with organized thrombus ( $\mathbf{F}$ and $\mathbf{G}$ ) at the aneurysm neck (arrow) and around the device struts. HPS, F; Movat Pentachrome, G. Figure is available in color online only.

TABLE 2. Angiographic results

\begin{tabular}{|c|c|c|c|c|c|c|c|c|}
\hline \multirow[b]{2}{*}{$\begin{array}{c}\text { Group \& Aneurysm } \\
\text { Location }\end{array}$} & \multicolumn{4}{|c|}{ Immediately Post-Treatment } & \multicolumn{4}{|c|}{ At 3-Mo Follow-Up } \\
\hline & Score & $\begin{array}{l}\text { Median } \\
{[\mathrm{IQR}]}\end{array}$ & Overall & $\begin{array}{l}\text { Adequate } \\
\text { Occl, n (\%) }\end{array}$ & Score & $\begin{array}{l}\text { Median } \\
{[\mathrm{IQR}]}\end{array}$ & Overall & $\begin{array}{l}\text { Adequate } \\
\text { Occl, n (\%) }\end{array}$ \\
\hline Group 1 (MEDs only) & & & $2[2-3]$ & $2 / 16(12.5)$ & & & $1[0-2]$ & $11 / 16(68.7)$ \\
\hline Lat wall carotid, $n=2$ & 3,1 & $2[1.5-2.5]$ & & & 3,1 & $2[1.5-2.5]$ & & \\
\hline Carotid T-bifurcation, $n=3$ & $2,2,2$ & $2[2-2]$ & & & $3,1,1$ & $1[1-2]$ & & \\
\hline Lingual bifurcation, $n=11$ & $\begin{array}{r}3,1,2,3,2,2 \\
3,2,3,3,3\end{array}$ & $3[2-3]$ & & & $\begin{array}{r}0,2,1,2,0,0 \\
2,1,0,1,0\end{array}$ & $1[0-1.5]$ & & \\
\hline Group 2 (MEDs + coils) & & & $2[2-2]$ & $3 / 16(18.7)$ & & $1.5[1-2]$ & $1[0.75-2]$ & $9 / 16(56.2)$ \\
\hline Lat wall carotid, $n=1$ & 2 & 2 & & & 3 & 3 & & \\
\hline Carotid T-bifurcation, $n=4$ & $2,2,1,2$ & $2[1.75-2]$ & & & $2,2,1,1$ & & & \\
\hline Lingual bifurcation, $\mathrm{n}=11$ & $\begin{array}{r}2,1,2,3,2,2 \\
2,2,2,2,1\end{array}$ & $2[2-2]$ & & & $\begin{array}{r}0,3,1,2,1,2 \\
2,1,0,0,0\end{array}$ & $1[0-2]$ & & \\
\hline Group 3 (coils alone) & & & $1[1-2]$ & $10 / 16(62.5)$ & & & $1.5[0.75-2]$ & $8 / 16(50)$ \\
\hline Lat wall carotid, $n=3$ & $3,1,1$ & $1[1-2]$ & & & $2,1,2$ & $2[1.5-2]$ & & \\
\hline Carotid T-bifurcation, $n=3$ & $1,2,1$ & $1[1-1.5]$ & & & $2,2,1$ & $2[1.5-2]$ & & \\
\hline Lingual bifurcation, $n=10$ & $\begin{array}{c}1,2,0,1,1,1 \\
1,2,2,2\end{array}$ & $1[1-2]$ & & & $\begin{array}{c}1,2,2,1,2,2 \\
0,0,0,0\end{array}$ & $1[0-2]$ & & \\
\hline
\end{tabular}

Occl = occlusion 


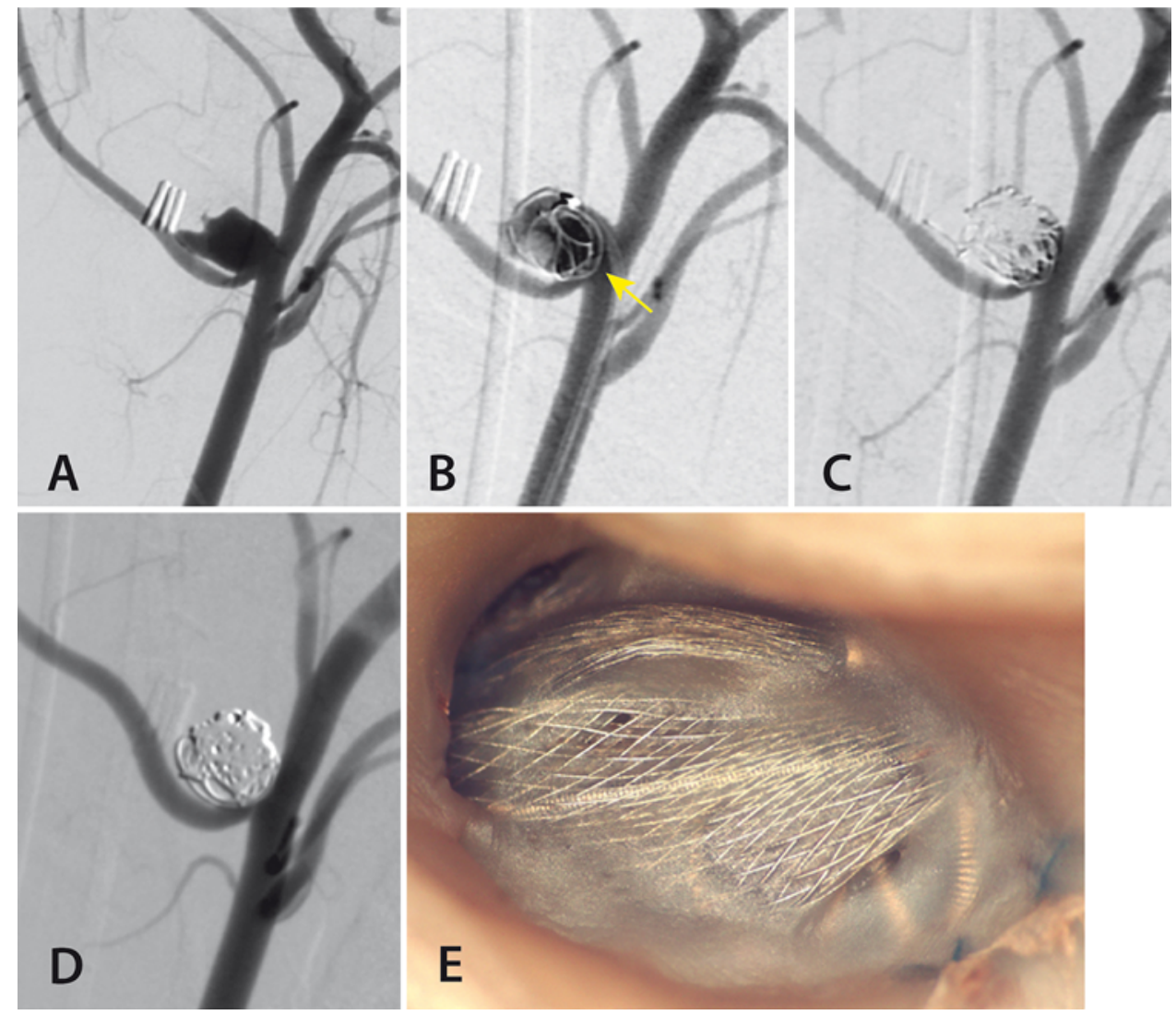

FIG. 3. Experimental aneurysm (A) treated with a single MED and coils that had good neck coverage by an opened petal (arrow in B) but that also resulted in branch ostial coverage. Results improved from immediately after treatment (C) to complete occlusion at 3 months (D), and the branch was still patent. Panel $\mathrm{E}$ shows the aneurysm neck closed by the IFD, which was covered by thick neointima. Figure is available in color online only.

in 11 of $16(68.7 \%, 95 \%$ CI $41.3 \%-89.0 \%)$ group 1,9 of 16 $(56.2 \%, 95 \%$ CI $29.9 \%-80.2 \%)$ group 2 , and 8 of $16(50 \%$, $95 \%$ CI $24.7 \%-75.3 \%$ ) group 3 aneurysms. Excluding the aneurysms that received bail-out stents did not change the results. Neither parent artery occlusion nor significant stenosis was observed in any animal.

Neointimal scores were similar for the 3 treated groups $(\mathrm{p}=0.66)$ (Table 3). Neointimal scores of 0 and 1 were found in 12 of 16 group $1(75 \%, 95 \%$ CI $47.6 \%-92.7 \%)$, 11 of 16 group $2(68.7 \%, 95 \%$ CI $41.3 \%-89.0 \%)$, and 11 of 16 group $3(68.7 \%, 95 \%$ CI $41.3 \%-89.0 \%)$ aneurysms. Typical pathological results are presented in Figs. 3 and 4. In all specimens, devices partially or completely closing the aneurysm necks were at least partially covered with neointima. In many cases the petals of the MED did not open properly (Supplementary Fig. 1). All aneurysms were filled with thrombus in various stages of organization. Recanalizing endothelialized crescents, connected to holes or neointimal defects, were present around the organizing thrombus in all incompletely occluded aneurysms treated with MEDs or coils.

Micropathological study of selected biopsy specimens demonstrated that neointima at the aneurysm neck was composed of connective tissue with collagen, covered with a layer of endothelial cells (Fig. 2). Inflammatory cells surrounding coils or MEDs were scant.

\section{Discussion}

The MED, conceived as a single IFD, could rarely be deployed into its intended position and shape. Consistently achieving contrast stasis within the aneurysm was not possible at the time of treatment with 1 stand-alone MED, at least in the 3 experimental aneurysm models that were studied. Attempts to close the aneurysm neck using multiple MEDs or a combination of MEDs and coils resulted in initial angiographic results that were inferior to controls, but final angiographic and pathological results were similar to standard treatment with platinum coils at 3 months.

The progressive aneurysm occlusion between initial and final angiographic results is witness to the fact that the device can work: some flow diversion was achieved, with resulting thrombosis, organization of thrombus within the sac, and neointimal formation on the segments of the device that were present at the neck. The angiographic comparison of initial results between MED and coiling is probably unfair, since the aim of coiling is to fill the aneurysm as completely as possible, and therefore residual flow is likely to be hidden by the dense coil mass. At this point, prior to clinical use in patients, we believe the crucial question is: does the new device offer any demonstrable benefits over standard treatment? In this regard, as 


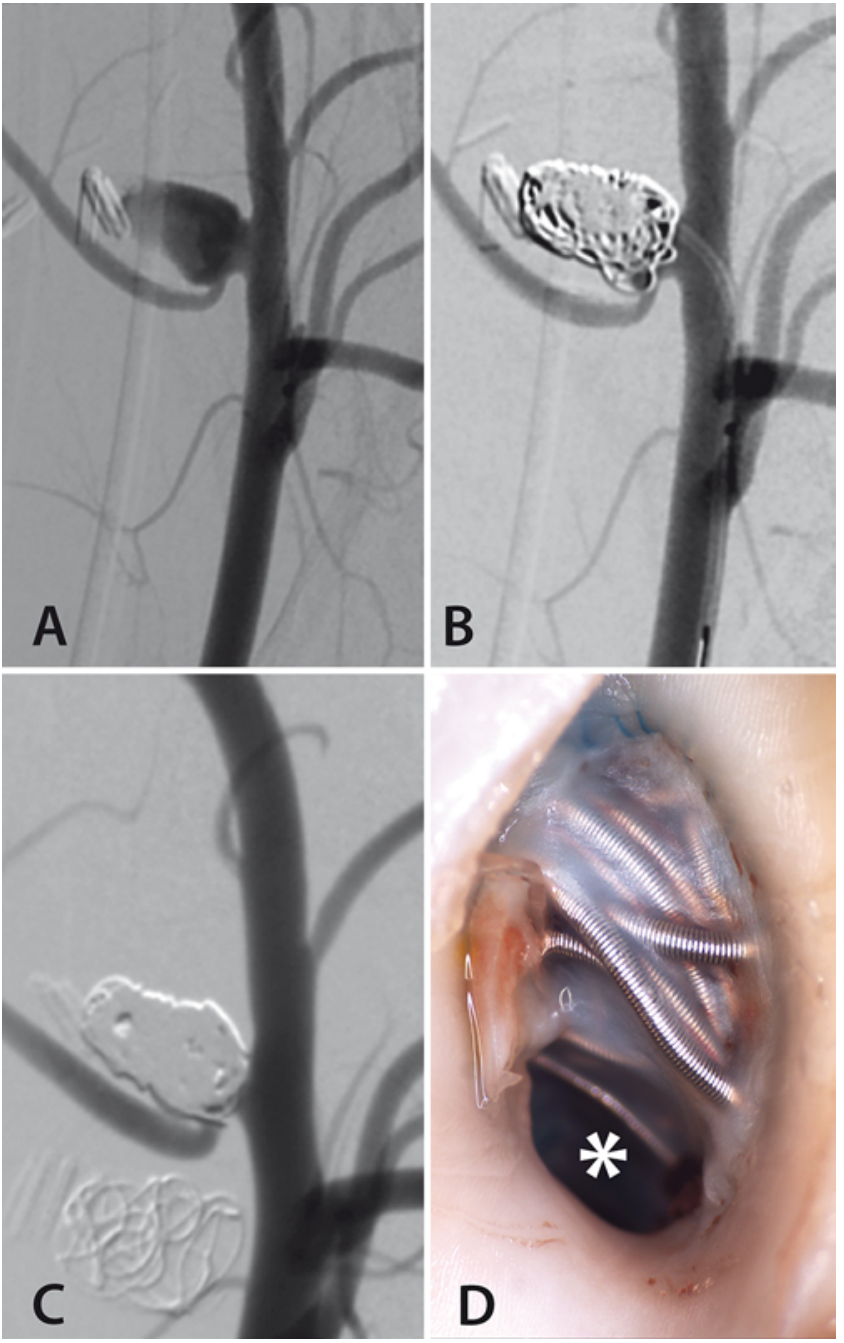

FIG. 4. Typical results following embolization of experimental aneurysm (A) with platinum coiling alone, showing good packing of the aneurysm (B), leading to complete occlusion at 3 months (C). Coils were well covered with neointima (D), while the lingual branch ostium (asterisk) remained patent. Figure is available in color online only.

in the clinical evaluation of a new treatment, a randomized comparison of a meaningful outcome with a control group is needed. In this case, follow-up angiographic results are most important, and no significant differences were shown. In addition, because pathological results at 3 months were also similar, we speculate that the recognized problem of angiographic recurrences after coiling, where the organizing thrombus retracts the coils toward the fundus, with concurrent expansion of endothelialized recanalizing crescents at the neck may also occur with MEDs whenever the neck is insufficiently closed. ${ }^{17}$

The first problem that was encountered was that the device, previously shown to consistently deploy into a spheroid flow-diverting object in vitro, could not always assume the intended shape in vivo when deployment was constrained by the less perfect but more realistic geometries of the in vivo aneurysm models we selected to do these experiments.
An important part of clinical reality is the heterogeneity of aneurysm morphologies. A device that needs to be tailored to fit a unique anatomy and perfectly positioned to be effective is unlikely to be clinically useful; this is particularly true when it is difficult to achieve even in the animal laboratory. Our choice of various aneurysm models was made because the intent was not to show that the device can work in optimal conditions, but rather the experiment was allowed to proceed such that it would inform what may be likely to happen in clinical practice. It could be argued that our animal experiment was not sufficiently (artificially) controlled to allow the device to behave as it did in vitro, but we believe this to be a strength of the experimental design, as it more appropriately anticipated how the device would behave in real clinical practice. Interestingly, the problems we encountered in the laboratory have also recently been reported to occur in practice. ${ }^{1,2}$

We knew from the very early use of the MED in patients that if some flow diversion could be achieved, it was infrequently optimal, resulting in residual or recurrent aneurysms at follow-up angiography. ${ }^{2,22}$ The next step was to assess whether the addition of multiple MEDs, or of coils within a framing MED, could achieve better neck closure and to compare the 2 methods. Thus the second problem we encountered was the technical challenge of adding more MEDs or coils to consistently position the low-porosity mesh at the level of the neck; adding more material (coils or MEDs) could displace a mesh petal that was initially at the neck, sometimes leading to coverage of an adjacent branch (Figs. 2 and 3), which often prevented deployment of additional MEDs or coils. Despite this occurrence, we did not observe any branch or parent artery occlusions, although we recognize that branches may have become occluded and then subsequently recanalized before final angiography. The end result was that neck closure at 3 months was not shown to be significantly different from what was seen with coiling. Previous preclinical studies assessing IFDs in rabbits have shown high (near-) complete occlusion rates at 3 months' follow-up: 7 of 8 aneurysms (87.5\%) and 5 of 6 aneurysms (83.3\%) with the LUNA $^{14}$ and the WEB devices, ${ }^{6}$ respectively. However, these results cannot be compared with results in canine models, as the smaller lateral wall rabbit aneurysms are simpler models that are almost always occluded irrespective of the device being tested.?

Admittedly, the experimental aneurysms we used were challenging, as shown by the rate of incomplete occlusions in both experimental and standard treatment groups, but we learn more when devices fail than when they succeed. ${ }^{7,9}$

On the positive side, the MED was easy to visualize and manipulate; like standard platinum coils, it was readily deployable and re-sheathable. If the MED is considered to be midway between an IFD and a coil, we believe future research should proceed in the coil direction. The clinical use of devices depends on many factors, not all of which are deliberately planned. The Guglielmi detachable coil that revolutionized the treatment of aneurysms was intended to produce electrothrombosis. Detachment of the electrode was meant to deal with the problem of what to do with the thrombus adhering to the device. In practice, we forgot about electrothrombosis and ended up packing the 
TABLE 3. Pathology results

\begin{tabular}{cllcc}
\hline & \multicolumn{3}{c}{ Neointimal Scores } \\
\cline { 2 - 5 } Group \& Aneurysm Location & \multicolumn{1}{c}{ Score } & Median [IQR] & Overall Median [IQR] & Adequate Occl, $n(\%)$ \\
\hline Group 1 (MEDs only) & & & 1 [0-1.25] & $12 / 16(75 \%)$ \\
\hline Lat wall carotid, $n=2$ & 2,1 & $1.5[1.25-1.75]$ & \\
\hline Carotid T-bifurcation, $n=3$ & $2,0,1$ & $1[0.5-1.5]$ & \\
\hline Lingual bifurcation, $n=11$ & $0,1,1,0,0,0,2,1,0,3,1$ & $1[0-1]$ & $110-2]$ & $1 / 16(68.7 \%)$ \\
\hline Group 2 (MEDs + coils) & & & & \\
\hline Lat wall carotid, $n=1$ & 2 & $1[1-1.5]$ & $11 / 16(68.7 \%)$ \\
\hline Carotid T-bifurcation, $n=4$ & $3,1,1,1$ & & $1[1-2]$ & \\
\hline Lingual bifurcation, $n=11$ & $0,2,1,0,0,3,2,0,0,0,1$ & $0[0-1.5]$ & & \\
\hline Group 3 (coils alone) & & & & \\
\hline Lat wall carotid, $n=3$ & $3,1,2$ & $2[1.5-2.5]$ & & \\
\hline Carotid T-bifurcation, $n=3$ & $3,2,1$ & $2[1.5-2.5]$ & & \\
\hline Lingual bifurcation, $n=10$ & $2,1,1,0,0,0,1,1,1,1$ & $1[0.25-1]$ & & \\
\hline
\end{tabular}

aneurysmal sac with multiple "electrodes." The key feature of coiling that made it successful was not the planned electrothrombosis, but the fact that aneurysms of any shape and size could be filled with coils, and the capacity to retrieve and reposition any coil loop that protruded from the sac. The MED showed similar features in experimental aneurysms. Perhaps, rather that attempting to reconstruct in vivo a device of a predetermined shape in an exact location, MEDs could be used to replace as many coils as possible, to hopefully improve neck closure and long-term angiographic results. The number of aneurysms studied in this experiment is far too small to exclude this possibility.

There are many limitations to this study. The variety of available devices did not match the dimensions of surgically created aneurysms in many cases. The number of aneurysms was small and because the follow-up period was 3 months, the long-term evolution of MED-treated aneurysms remains to be studied. Experimental models were surgical constructions in canines that differ widely from human intracranial aneurysms. As always, one must be cautious in extrapolating these results to the clinical realm.

\section{Conclusions}

Endovascular treatment of experimental aneurysms with the MED showed angiographic occlusion and neointimal scores at 3 months that were similar to those for standard coiling.

\section{References}

1. Aguilar Perez M, Bhogal P, Martinez Moreno R, Bäzner H, Ganslandt O, Henkes H: The Medina Embolic Device: early clinical experience from a single center. J Neurointerv Surg 9:77-87, 2017

2. Bhogal P, Brouwer PA, Yeo L, Svensson M, Söderman M: The Medina Embolic Device: Karolinska experience. Interv Neuroradiol 24:4-13, 2018

3. Caroff J, Mihalea C, Dargento F, Neki H, Ikka L, Benachour $\mathrm{N}$, et al: Woven Endobridge (WEB) Device for endovascular treatment of ruptured intracranial wide-neck aneurysms: a single-center experience. Neuroradiology 56:755-761, 2014
4. Darsaut TE, Findlay JM, Magro E, Kotowski M, Roy D, Weill A, et al: Surgical clipping or endovascular coiling for unruptured intracranial aneurysms: a pragmatic randomised trial. J Neurol Neurosurg Psychiatry 88:663-668, 2017

5. Darsaut TE, Raymond J: The design of the STenting in Aneurysm Treatments (STAT) trial. J Neurointerv Surg 4:178-181, 2012

6. Ding YH, Dai D, Schroeder D, Kadirvel R, Kallmes DF: Experimental testing of the dual-layer Woven EndoBridge device using an elastase-induced aneurysm model in rabbits. Interv Neuroradiol 22:299-303, 2016

7. Fahed R, Darsaut TE, Gentric JC, Farzin B, Salazkin I, Gevry G, et al: Flow diversion: what can clinicians learn from animal models? Neuroradiology 59:255-261, 2017

8. Fahed R, Gentric JC, Salazkin I, Gevry G, Raymond J, Darsaut TE: Flow diversion of bifurcation aneurysms is more effective when the jailed branch is occluded: an experimental study in a novel canine model. J Neurointerv Surg 9:311315, 2017

9. Fahed R, Raymond J, Ducroux C, Gentric JC, Salazkin I, Ziegler D, et al: Testing flow diversion in animal models: a systematic review. Neuroradiology 58:375-382, 2016

10. German WJ, Black SP: Experimental production of carotid aneurysms. N Engl J Med 250:104-106, 1954

11. Kamran M, Yarnold J, Grunwald IQ, Byrne JV: Assessment of angiographic outcomes after flow diversion treatment of intracranial aneurysms: a new grading schema. Neuroradiology 53:501-508, 2011

12. Kilkenny C, Browne W, Cuthill IC, Emerson M, Altman DG: Animal research: reporting in vivo experiments-the ARRIVE guidelines. J Cereb Blood Flow Metab 31:991-993, 2011

13. Kung DK, Policeni BA, Capuano AW, Rossen JD, Jabbour PM, Torner JC, et al: Risk of ventriculostomy-related hemorrhage in patients with acutely ruptured aneurysms treated using stent-assisted coiling. J Neurosurg 114:1021-1027, 2011

14. Kwon SC, Ding YH, Dai D, Kadirvel R, Lewis DA, Kallmes DF: Preliminary results of the Luna aneurysm embolization system in a rabbit model: a new intrasaccular aneurysm occlusion device. AJNR Am J Neuroradiol 32:602-606, 2011

15. McDougall CG, Johnston SC, Gholkar A, Barnwell SL, Vazquez Suarez JC, Massó Romero J, et al: Bioactive versus bare platinum coils in the treatment of intracranial aneurysms: the MAPS (Matrix and Platinum Science) trial. AJNR Am J Neuroradiol 35:935-942, 2014

16. Pierot L, Gubucz I, Buhk JH, Holtmannspötter M, Herbre- 
teau D, Stockx L, et al: Safety and efficacy of aneurysm treatment with the WEB: results of the WEBCAST 2 study. AJNR Am J Neuroradiol 38:1151-1155, 2017

17. Raymond J, Darsaut T, Salazkin I, Gevry G, Bouzeghrane F: Mechanisms of occlusion and recanalization in canine carotid bifurcation aneurysms embolized with platinum coils: an alternative concept. AJNR Am J Neuroradiol 29:745-752, 2008

18. Raymond J, Gentric JC, Darsaut TE, Iancu D, Chagnon M, Weill A, et al: Flow diversion in the treatment of aneurysms: a randomized care trial and registry. $\mathbf{J}$ Neurosurg 127:454462, 2017

19. Raymond J, Guilbert F, Weill A, Georganos SA, Juravsky L, Lambert A, et al: Long-term angiographic recurrences after selective endovascular treatment of aneurysms with detachable coils. Stroke 34:1398-1403, 2003

20. Raymond J, Klink R, Chagnon M, Barnwell SL, Evans AJ, Mocco J, et al: Hydrogel versus bare platinum coils in patients with large or recurrent aneurysms prone to recurrence after endovascular treatment: a randomized controlled trial. AJNR Am J Neuroradiol 38:432-441, 2017

21. Raymond J, Salazkin I, Georganos S, Guilbert F, Desfaits AC, Gevry G, et al: Endovascular treatment of experimental wide neck aneurysms: comparison of results using coils or cyanoacrylate with the assistance of an aneurysm neck bridge device. AJNR Am J Neuroradiol 23:1710-1716, 2002

22. Sourour NA, Vande Perre S, Maria FD, Papagiannaki C, Gabrieli J, Pistocchi S, et al: Medina ${ }^{\circledR}$ Embolization Device for the treatment of intracranial aneurysms: safety and angiographic effectiveness at 6 months. Neurosurgery 82:155162,2018

23. Turk AS, Maia O, Ferreira CC, Freitas D, Mocco J, Hanel $\mathrm{R}$ : Periprocedural safety of aneurysm embolization with the Medina Coil System: the early human experience. J Neurointerv Surg 8:168-172, 2016
24. White PM, Lewis SC, Nahser H, Sellar RJ, Goddard T, Gholkar A: HydroCoil Endovascular Aneurysm Occlusion and Packing Study (HELPS trial): procedural safety and operator-assessed efficacy results. AJNR Am J Neuroradiol 29:217-223, 2008

\section{Disclosures}

This work was supported by a research grant from Medtronic/ Covidien. The funding source had no role in the study design or the drafting of the manuscript

\section{Author Contributions}

Conception and design: Raymond, Darsaut, Salazkin. Acquisition of data: Raymond, Fahed, Darsaut, Salazkin. Analysis and interpretation of data: all authors. Drafting the article: all authors. Critically revising the article: Raymond, Fahed, Darsaut, Salazkin. Reviewed submitted version of manuscript: Raymond, Fahed, Darsaut, Salazkin. Approved the final version of the manuscript on behalf of all authors: Raymond. Statistical analysis: Fahed. Administrative/technical/material support: Gevry. Study supervision: Raymond, Darsaut.

\section{Supplemental Information}

\section{Online-Only Content}

Supplemental material is available with the online version of the article.

Supplementary Table and Figure. https://thejns.org/doi/suppl/ 10.3171/2018.5.JNS18326.

\section{Correspondence}

Jean Raymond: CHUM, Notre-Dame Hospital, Montreal, QC, Canada. jean.raymond@umontreal.ca. 